OPEN ACCESS

Edited by: Lucio Dell'Atti,

Marche Polytechnic University, Italy

Reviewed by:

Rupali Das,

Michigan State University,

United States

Kamalakannan Rajasekaran, Genentech, Inc., United States

${ }^{*}$ Correspondence:

Olivier Dormond

olivier.dormond@chuv.ch

Specialty section:

This article was submitted to

Signaling,

a section of the journal Frontiers in Cell and Developmental

Biology

Received: 30 November 2020

Accepted: 15 February 2021

Published: 15 March 2021

Citation:

Faes S, Demartines $N$ and Dormond O (2021) Mechanistic Target of Rapamycin Inhibitors in Renal Cell Carcinoma: Potential, Limitations, and

Perspectives.

Front. Cell Dev. Biol. 9:636037. doi: 10.3389/fcell.2021.636037

\section{Mechanistic Target of Rapamycin Inhibitors in Renal Cell Carcinoma: Potential, Limitations, and Perspectives}

\author{
Seraina Faes, Nicolas Demartines and Olivier Dormond * \\ Department of Visceral Surgery, Lausanne University Hospital, University of Lausanne, Lausanne, Switzerland
}

Several elements highlight the importance of the mechanistic target of rapamycin (mTOR) in the biology of renal cell carcinoma (RCC). mTOR signaling pathway is indeed frequently activated in RCC, inducing cancer cell proliferation and survival. In addition, mTOR promotes tumor angiogenesis and regulates the expression of hypoxia-inducible factors that play an important role in a subset of RCC. Despite mTOR protumorigenic effects, mTOR inhibitors have failed to provide long-lasting anticancer benefits in RCC patients, highlighting the need to readdress their role in the treatment of RCC. This review aims to present the rationale and limitations of targeting mTOR in RCC. Future roles of mTOR inhibitors in the treatment of RCC are also discussed, in particular in the context of immunotherapies.

Keywords: mTOR, rapalogs, renal cell carcinoma, HIF- $\alpha$, angiogenesis

\section{INTRODUCTION}

Renal cell carcinoma (RCC), which originates from the kidney epithelium, is the most frequent form of kidney cancer (Hsieh et al., 2017b; Nabi et al., 2018; Kotecha et al., 2019). RCC comprises several histological and molecular subtypes of which clear cell RCC is the most frequent (Moch et al., 2016). Curative surgery is possible in patients with localized RCC (Ljungberg et al., 2015). Unfortunately, many patients present in advanced, metastatic stages at diagnosis, and progression of a localized to an advanced stage is frequent despite surgery. Since advanced RCC is associated with high mortality, a strong need exists to develop appropriate systemic treatments. In this context, major progress has been achieved recently, and today, several therapeutic options exist, including immunotherapy and targeted therapies against vascular endothelial growth factor (VEGF) or mechanistic target of rapamycin (mTOR) signaling pathway (Hsieh et al., 2017b; Kotecha et al., 2019). Nevertheless, the efficacy of these therapies is limited, and disease progression is inevitable in most patients. Therefore, it is important to gain further knowledge regarding the biology of RCC in order to design successful therapies.

mTOR is a serine/threonine kinase that belongs to two distinct protein complexes, named mTORC1 and mTORC2. mTORC1 controls several processes involved in cell growth and proliferation including protein, lipid, and nucleotide synthesis (Saxton and Sabatini, 2017). Inhibition of mTORC1 by allosteric inhibitors generally termed rapalogs results in decreased cell proliferation and accordingly provides anticancer benefits (Waldner et al., 2016; Torii et al., 2020) in different types of cancer, including advanced RCC (Tian et al., 2019). The anticancer effect is however limited, and rapalogs are mostly prescribed as second- or third-line therapies. Although 
initially viewed as promising, mTORC1 inhibitors did not meet the expectations in RCC, and their roles need therefore to be readdressed. Here, the biologic rationale and limitations to use mTOR inhibitors in advanced RCC are reviewed. In addition, future roles that mTOR inhibitors might endorse in the treatment of advanced RCC are discussed.

\section{ACTIVATION OF MECHANISTIC TARGET OF RAPAMYCIN IN RENAL CELL CARCINOMA}

A major reason to target mTOR in RCC relies on the observation that, overall, mTOR contributes to cancer cell proliferation and survival, and mTOR signaling pathway is often activated in advanced RCC (Figure 1). In fact, genetic alterations of components of mTOR signaling pathway are frequently observed in RCC, underscoring the possible importance of mTOR in RCC development. For instance, $28 \%$ of clear cell RCC presents activating mutations of $\mathrm{PI} 3 \mathrm{~K} / \mathrm{AKT} / \mathrm{mTOR}$ signaling pathway that correlate with worse outcome (Cancer Genome Atlas Research, 2013). Similarly, 23\% of chromophobe RCC displays genetic modifications of mTOR signaling pathway (Davis et al., 2014). Furthermore, expression of the activated forms of various components of the PI3K/AKT/mTOR signaling pathway was detected in a high percentage of RCC by immunohistochemistry (Lin et al., 2006; Pantuck et al., 2007; Abou Youssif et al., 2011).

mTOR inhibitors exert their antitumor effects in part by reducing cancer cell proliferation via blocking the G1-S cell cycle transition (Dufour et al., 2011). Decreased expression of cyclin D1 and upregulated levels of $\mathrm{p} 27^{\mathrm{Kip} 1}$ have been observed in cancer cells as molecular basis for cell cycle blockage. Consistent with these findings, mTOR inhibitors induce G1 block in RCC cell lines in vitro and reduce cancer cell proliferation in RCC xenografts (Luan et al., 2003; Zhang et al., 2013; Zheng et al., 2015). Despite promising preclinical experiments, mTOR targeting agents have been less successful than expected in RCC patients. An initial phase III study tested the rapalog temsirolimus against interferon- $\alpha$ among patients with advanced RCC and poor prognosis (Hudes et al., 2007). Median overall survival was longer in the temsirolimus group compared with the interferon- $\alpha$ group (10.9 vs. 7.3 months). Similarly, everolimus was reported to increase progression-free survival compared with placebo in advanced RCC patients that had progressed on multi-targeted tyrosine kinase inhibitors (Motzer et al., 2008). Therefore, despite extensive activation of the PI3K/AKT/mTOR signaling pathway in advanced RCC, rapalogs display modest anticancer activity, suggesting that tumors do not depend on mTORC1 for growth and survival. This could be explained by the fact that upstream activators of mTORC1 such as PI3K or AKT activate several other downstream effectors that possess protumorigenic effects besides mTORC1 (Faes and Dormond, 2015). In addition, several resistance mechanisms might explain the limited efficacy of rapalogs including rapalogresistant mutations of $\mathrm{mTOR}$, activation of alternate proliferative pathways following mTORC1 inhibition, or tumor heterogeneity (Faes et al., 2017a). Finally, rapalogs only partially inhibit

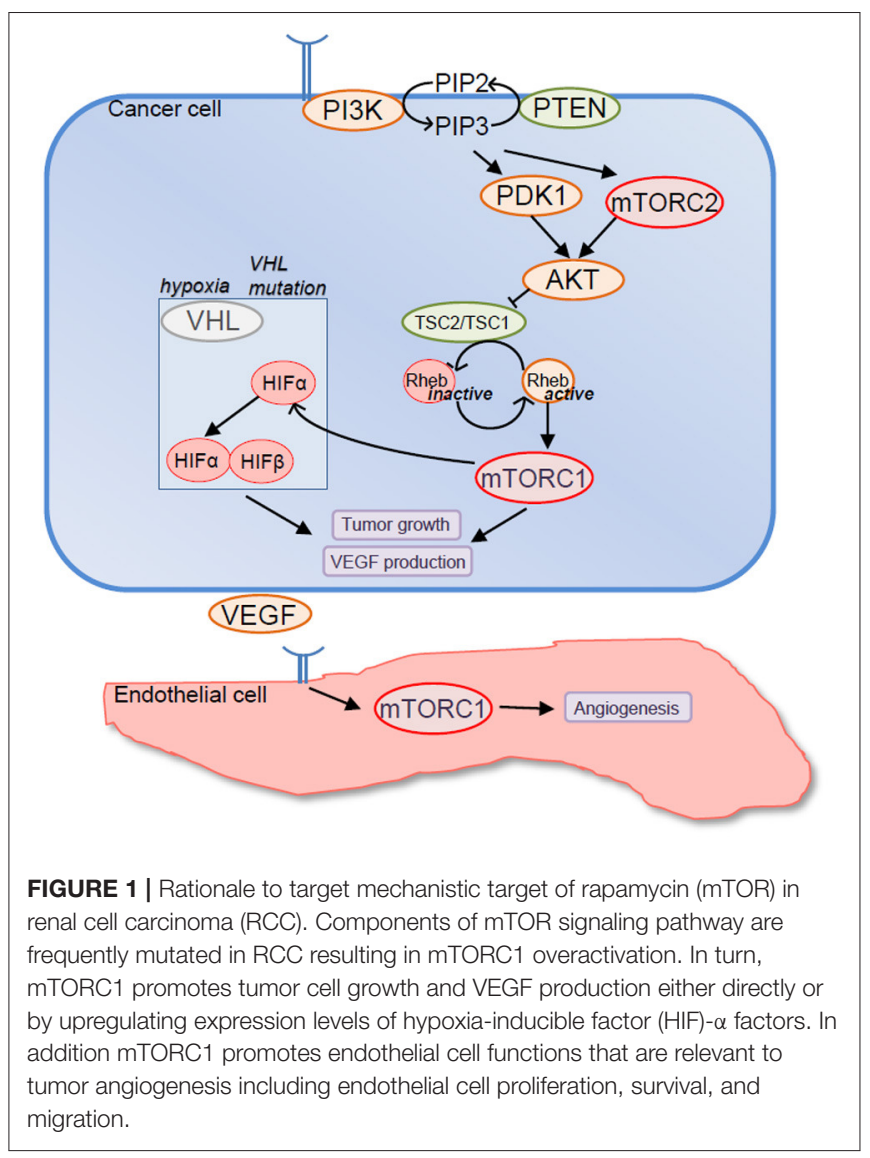

mTORC1, and therefore, a complete mTORC1 inhibition might be necessary to achieve better clinical outcome (Thoreen et al., 2009). In this context, kinase inhibitors of mTOR that display a complete inhibition of mTORC1 and that in contrast to rapalogs also inhibit mTORC2 have been developed (Benjamin et al., 2011). Preclinical studies have demonstrated that kinase inhibitor of mTOR are superior to rapalogs in RCC models (Cho et al., 2010; Ingels et al., 2014; Zheng et al., 2015). Unfortunately, such results were not confirmed in clinical settings. Two randomized phase 2 trials showed that the kinase inhibitor of mTOR AZD2014 (Powles et al., 2016b) and the dual PI3K/mTOR inhibitor GDC-0980 (Powles et al., 2016a) were inferior to everolimus in RCC patients who had progressed following exposure to VEGF pathway targeting therapies. Finally, a third-generation inhibitor named rapalink-1 and composed of rapamycin linked to the kinase inhibitor of mTOR MLN0128 provides improved anticancer efficacy in RCC models compared with temsirolimus (Kuroshima et al., 2020).

Nevertheless, a small minority of RCC patients respond to rapalogs, highlighting the need to identify biomarkers that could predict patients benefiting from rapalogs. Conceptually, cancers in which mTOR is a driving force with few heterogeneity represent the ideal candidate (Rodriguez-Moreno et al., 2017). In this context, the histologic subtype is not helpful in selecting patients. It was indeed reported that temsirolimus was efficient 
in patients regardless of tumor histology (Dutcher et al., 2009). Similar results were observed in a retrospective study analyzing the effect of temsirolimus and everolimus in RCC with sarcomatoid or non-clear cell histologies (Voss et al., 2014a). Genetic analysis of mTOR pathway mutations has also provided mitigated results so far (Table 1). In fact, two out of five patients who showed exceptional response to rapalogs lacked mTOR signaling pathway activating mutations (Voss et al., 2014b). Similarly, in another cohort of RCC patients treated with rapalogs, $56 \%$ of responders had no genetic finding to explain their response (Kwiatkowski et al., 2016). Epigenetic mechanisms or direct effects of rapalogs on the tumor microenvironment might be at play. Nevertheless, mutations in tuberous sclerosis proteins TSC1 or TSC2, close upstream regulators of mTORC1, and $m T O R$ are more common among rapalog responders (Kwiatkowski et al., 2016; Roldan-Romero et al., 2017). More promisingly, loss of PTEN expression, and not loss-offunction mutations, has recently been associated with everolimus therapeutic response (Voss et al., 2019; Roldan-Romero et al., 2020). Clearly, additional work is however required to identify reliable and robust combinations of biomarkers of response that can be used in clinic. Interestingly, a complete analysis of exceptional responders to rapalogs (mean progression-free survival of 28 months) revealed convergent mutations resulting in mTOR pathway activation (Voss et al., 2014b). It was therefore proposed that RCC development behaves rather like a braided river than a branching tree (Hsieh and Cheng, 2016; Hsieh et al., 2017a). This parallel convergent evolution of kidney cancer would thus offer significant therapeutic opportunities despite tumor heterogeneity.
Since rapalogs alone provide little benefits, several trials have explored mTOR inhibitors in combination therapies. In particular, combinations of rapalogs with anti-angiogenic drugs including, sorafenib, sunitinib, and bevacizumab have been tested (Ravaud et al., 2013). Most trials were however discontinued or required dose modification due to drug toxicity. In fact mTOR inhibitors are associated with substantial side effects such as mucositis, rash, myelosuppression, hyperglycemia, hypophosphatemia, hypercholesterolemia, and pneumonitis, limiting their application in cancer patients (Rodriguez-Pascual et al., 2010; Pallet and Legendre, 2013). Nevertheless, combining lenvatinib with everolimus resulted in an acceptable safety profile and has been approved for RCC patients who had received prior antiangiogenic treatments (Motzer et al., 2015).

\section{ANTI-ANGIOGENIC EFFECTS OF MECHANISTIC TARGET OF RAPAMYCIN INHIBITORS IN RENAL CELL CARCINOMA}

RCCs are highly vascularized tumors, and the therapeutic benefits of anti-VEGF signaling therapies underline the role of angiogenesis in RCC development (Hsieh et al., 2017b). In this context, targeting mTOR represents a treatment strategy, as mTOR controls several processes implicated in tumor angiogenesis (Faes et al., 2017b). In fact, mTOR is an important signaling intermediary that regulates endothelial functions relevant to angiogenesis such as proliferation, survival, and migration (Akselband et al., 1991; Bruns et al., 2004; Dormond et al., 2007). Furthermore, mTOR modulates tumor angiogenesis

TABLE 1 | RCC genetic analysis and response to rapalogs.

\begin{tabular}{|c|c|c|c|c|}
\hline \multirow{2}{*}{$\begin{array}{l}\text { Patients } \\
79 \text { selected RCC patients treated } \\
\text { with rapalogs }\end{array}$} & \multirow{2}{*}{$\begin{array}{l}\text { Genetic alterations } \\
\text { Mutation } \\
\text { TSC1 or TSC2 or mTOR } \\
\text { No mTOR pathway mutation }\end{array}$} & \multicolumn{2}{|c|}{ Results } & \multirow{2}{*}{$\begin{array}{l}\text { References } \\
\text { Kwiatkowski et al., } 2016\end{array}$} \\
\hline & & $\begin{array}{c}\text { Responders }^{a} \\
28 \% \\
56 \%\end{array}$ & $\begin{array}{c}\text { Non-responders } \\
11 \% \\
78 \%\end{array}$ & \\
\hline $\begin{array}{l}45 \mathrm{RCC} \text { patients treated with } \\
\text { rapalogs (five harboring mTOR related } \\
\text { mutations) }\end{array}$ & $\begin{array}{l}\text { Mutation } \\
\text { mTOR early event } \\
\text { mTOR } \\
\text { mTOR } \\
\text { TSC1 } \\
\text { TSC2 }\end{array}$ & $\begin{array}{l}\text { Response } \\
\text { PR } \\
\text { SD } \\
\text { SD } \\
\text { PR } \\
\text { PD }\end{array}$ & $\begin{array}{c}\text { PFS (months) } \\
89 \\
9 \\
3 \\
11\end{array}$ & Roldan-Romero et al., 2017 \\
\hline Exceptional responder & $\begin{array}{l}\text { Mutation } \\
\text { mTOR early event }\end{array}$ & $\begin{array}{l}\text { Disease } \\
\text { temsirc }\end{array}$ & $\begin{array}{l}\text { fter } 8 \text { years' } \\
\text { treatment }\end{array}$ & $\begin{array}{l}\text { Rodriguez-Moreno et al., } \\
2017\end{array}$ \\
\hline 184 everolimus treated RCC patients & $\begin{array}{l}\text { IHC staining } \\
\text { PTEN negative } \\
\text { PTEN positive }\end{array}$ & $\begin{array}{r}\mathrm{PF} \\
\text { No correlatio } \\
m T C\end{array}$ & $\begin{array}{l}\text { TSths) } \\
\text { TSC1, TSC2 or } \\
\text { tations }\end{array}$ & Voss et al., 2019 \\
\hline 105 rapalogs treated RCC patients & $\begin{array}{l}\text { IHC staining } \\
\text { PTEN negative } \\
\text { PTEN positive }\end{array}$ & $\begin{array}{c}\text { Responders }^{c} \\
48 \% \\
18 \%\end{array}$ & $\begin{array}{l}\text { Non-responders }^{d} \\
52 \% \\
82 \%\end{array}$ & Roldan-Romero et al., 2020 \\
\hline
\end{tabular}

PR, partial response; SD, stable disease; $P D$, progressive disease; PFS, progression-free survival; IHC, immunohistochemistry; RCC, renal cell carcinoma.

a Responders: PR or $S D$ with any tumor shrinkage for 6 months.

${ }^{b}$ Non-responders: $P D$ during the first 3 months of therapy.

${ }^{c}$ Responders: PR or SD and at least 6 months PFS.

dNon-responders: PD or SD of $<6$ months PFS. 
by regulating the production of pro-angiogenic factors in particular VEGF (Guba et al., 2002). Accordingly, mTOR inhibitors decrease tumor angiogenesis in a variety of preclinical models (Faes et al., 2017b). However, the contribution of the anti-angiogenic effects of rapalogs in RCC patients remains to be demonstrated. Of note, combining the anti-VEGF bevacizumab to temsirolimus did not provide better results than bevacizumab with interferon- $\alpha$, suggesting that bevacizumab and temsirolimus share inhibition of angiogenesis as a common anticancer effect (Rini et al., 2014). Nevertheless, the limited efficacy of rapalogs in advanced RCC challenges the anti-angiogenic efficacy of mTOR inhibitors. In fact, mTOR inhibitors had no impact on microvessel density of RCC xenografts, suggesting that in certain circumstances, tumor blood vessels are not sensitive to mTOR inhibitors, or the anti-angiogenic effects might only be transient (Cho et al., 2010; Ellis et al., 2012).

\section{REGULATION OF HYPOXIA-INDUCIBLE FACTORS BY MECHANISTIC TARGET OF RAPAMYCIN}

Clear cell RCC frequently harbors loss-of-function mutations of the tumor suppressor gene Von Hippel-Lindau (VHL). Consequently, hypoxia-inducible factors (HIF-1 $\alpha$ and HIF-2 $\alpha$ ) accumulate, leading to a constant hypoxic tumor response that promotes tumor growth and angiogenesis despite the presence of oxygen (Patel et al., 2006; Shen and Kaelin, 2013). Therefore, targeting HIFs might influence RCC progression (Schodel et al., 2016). Interestingly, in contrast to initial thoughts, emerging evidence has now demonstrated a divergent role for HIF- $\alpha$ factors in RCC biology where HIF-1 $\alpha$ reduces and HIF- $2 \alpha$ promotes RCC growth (Kondo et al., 2002, 2003; Shen et al., 2011; Gudas et al., 2014; Hoefflin et al., 2020).

Several reports have evidenced that mTOR decreases expression of HIF- $\alpha$ factors and therefore might influence RCC growth (Faes et al., 2017b). Consistent with this hypothesis, it was demonstrated that VHL mutation determines RCC sensitivity to temsirolimus in a mouse model of RCC (Thomas et al., 2006). Rapalogs decrease HIF- $1 \alpha$ expression via different mechanisms including HIF- $1 \alpha$ mRNA transcription, mRNA translation, protein stabilization, and transcriptional activity (Faes et al., 2017b). In contrast, HIF-2 $\alpha$ expression depends on mTORC2 activity and is accordingly not affected by rapalogs (Toschi et al., 2008). In the context of RCC, opposing results have been reported regarding the effect of mTOR inhibitors on HIF- $\alpha$ factor expression. It was shown that temsirolimus reduces both HIF- $1 \alpha$ and HIF- $2 \alpha$ expression in RCC in vitro (Thomas et al., 2006). In contrast, whereas the dual PI3K/mTOR inhibitor NVP-BEZ235 decreased HIF-2 $\alpha$ expression in 786-0, A498, Caki-1, and Caki-2 RCC cell lines, rapamycin had no significant effects (Cho et al., 2010). Taken together, these studies highlight the complex interrelationship between mTOR and HIF- $\alpha$ factors and suggest that preferential inhibition of HIF- $1 \alpha$ expression over HIF- $2 \alpha$ by rapalogs might provide detrimental protumorigenic signals. Nevertheless, a complete understanding of the role of HIF- $\alpha$ factors in RCC and the consequences of mTOR inhibition on their activities is necessary.

\section{FUTURE DIRECTION: COMBINING MECHANISTIC TARGET OF RAPAMYCIN INHIBITORS WITH IMMUNOTHERAPIES}

Following major therapeutic success by immunotherapy in melanoma, lot of efforts are deployed to design immunotherapybased protocols in RCC. Interleukin- 2 and interferon- $\alpha$ were initially used in patients with advanced RCC, suggesting that RCC might be particularly sensitive to immunotherapies. Accordingly, numerous clinical trials are currently exploring the effects of immunotherapy alone or in combination with various targeted therapies (Garje et al., 2020). Since rapalogs are mainly used to prevent rejection of transplanted organs, their use with immunotherapies seems aberrant at first look. However, emerging studies have demonstrated that mTOR inhibitors display immunostimulatory effects. Rapamycin increases memory $\mathrm{CD}^{+} \mathrm{T}$ cell differentiation following viral infection (Araki et al., 2009). Rapamycin treatment also induces stem-cell like memory $\mathrm{T}$ cells during activation of human naïve $\mathrm{T}$ cells (Scholz et al., 2016). In cancer, preclinical studies have shown that rapalogs enhance the tumor response to different types of immunotherapies including vaccines, adoptive $\mathrm{T}$ cell therapy, and checkpoint inhibitors (Thomas et al., 2011; Wang et al., 2011; Amiel et al., 2012; Li et al., 2012; Diken et al., 2013; Mineharu et al., 2014; Moore et al., 2016). Therefore, additional studies are needed to fully characterize the conditions in which mTOR inhibition results in immune stimulation or inhibition. Interestingly, the immune modulatory properties of rapalogs were assessed in RCC patients, and results confirmed that mTOR inhibitors provide opposing effects on the antitumor immune response (Beziaud et al., 2016; Huijts et al., 2017). In most patients, the rapalog everolimus promoted expansion of FoxP $\mathrm{P}_{3}^{+}$regulatory $\mathrm{T}$ cells $\left(\mathrm{T}_{\text {regs }}\right)$ and increased spontaneous tumor-specific $\mathrm{TH}_{1}$ response. Importantly, in a subset of patients, everolimus decreased $\mathrm{T}_{\text {regs }}$ levels while increasing $\mathrm{TH}_{1}$ response, which was associated with a longer progression-free survival. This suggests that the antitumor effects of rapalogs occur in part via modulation of the antitumor immune response and provide an additional rationale to combine mTOR inhibitors with immunotherapies.

The endothelial barrier is an important obstacle to recognize when considering combining anticancer agents with immunotherapies (Schmittnaegel and De Palma, 2017; Uldry et al., 2017). In fact, tumor blood perfusion is frequently reduced due to abnormal blood vessels, resulting in hypoxia and decreased delivery of anticancer agents and immune cells to tumors (Martin et al., 2019). Accordingly, tumor blood vessel normalization with anti-angiogenic drugs improves cancer immunotherapy by in part augmenting $\mathrm{T}$ cell extravasation (Allen et al., 2017; Schmittnaegel et al., 2017; Mpekris et al., 2020). Preclinical studies demonstrated contrasting results regarding the effects of mTOR inhibitors on tumor blood vessel normalization. On the one hand, reduction of vessel permeability 
and increased tumor perfusion by mTOR inhibitors were observed in different cancer models (Schnell et al., 2008; Zhang et al., 2011; Myers et al., 2012). On the other hand, absence of effects was also noted (Lane et al., 2009; Ellis et al., 2012). Therefore, applying mTOR inhibitors in conditions where they induce vessel normalization might be particularly beneficial with immunotherapies. Tumor blood vessels also actively participate to the recruitment of leukocytes into tumors by expressing adhesion molecules such as intercellular adhesion molecule-1 (ICAM-1) or vascular cell adhesion molecule-1 (VCAM-1). In addition, they modulate $\mathrm{T}$ cell activity by expressing MHC class I and class II as well as co-stimulatory and co-inhibitory molecules (Choi et al., 2004). Of note, it was reported that mTOR inhibitors upregulate PD-L1 and PD-L2 and reduce VCAM-1 expression on endothelial cells (Wang et al., 2013, 2014). Consequently, rapamycin pretreatment of human arterial allografts decreased infiltration of artery intima by effector T cells. Although these findings need to be investigated in tumor models, they suggest that mTOR inhibitors might reinforce the tumor endothelial barrier and therefore counteract their benefits in the context of immunotherapy.

\section{CONCLUSIONS}

Despite clear implications of mTOR signaling pathway in RCC development and progression, inhibition of mTOR through rapalogs did not provide major and long-lasting anticancer benefits in patients. Whereas, mTOR is frequently activated in RCC and participates in tumor growth, RCC harbors major genetic heterogeneity, implying that many driving forces, not limited to mTOR, participate in tumor growth. Combination

\section{REFERENCES}

Abou Youssif, T., Fahmy, M. A., Koumakpayi, I. H., Ayala, F., Al Marzooqi, S., Chen, G., et al. (2011). The mammalian target of rapamycin pathway is widely activated without PTEN deletion in renal cell carcinoma metastases. Cancer 117, 290-300. doi: 10.1002/cncr.25402

Akselband, Y., Harding, M. W., and Nelson, P. A. (1991). Rapamycin inhibits spontaneous and fibroblast growth factor beta-stimulated proliferation of endothelial cells and fibroblasts. Transplant Proc. 23, 2833-2836.

Allen, E., Jabouille, A., Rivera, L. B., Lodewijckx, I., Missiaen, R., Steri, V., et al. (2017). Combined antiangiogenic and anti-PD-L1 therapy stimulates tumor immunity through HEV formation. Sci. Transl. Med. 9:eaak9679. doi: 10.1126/scitranslmed.aak9679

Amiel, E., Everts, B., Freitas, T. C., King, I. L., Curtis, J. D., Pearce, E. L., et al. (2012). Inhibition of mechanistic target of rapamycin promotes dendritic cell activation and enhances therapeutic autologous vaccination in mice. J. Immunol. 189, 2151-2158. doi: 10.4049/jimmunol.1103741

Araki, K., Turner, A. P., Shaffer, V. O., Gangappa, S., Keller, S. A., Bachmann, M. F., et al. (2009). mTOR regulates memory CD8 T-cell differentiation. Nature 460, 108-112. doi: 10.1038/nature08155

Benjamin, D., Colombi, M., Moroni, C., and Hall, M. N. (2011). Rapamycin passes the torch: a new generation of mTOR inhibitors. Nat. Rev. Drug Discov. 10, 868-880. doi: 10.1038/nrd3531

Beziaud, L., Mansi, L., Ravel, P., Marie-Joseph, E. L., Laheurte, C., Rangan, L., et al. (2016). Rapalogs efficacy relies on the modulation of antitumor T-cell immunity. Cancer Res. 76, 4100-4112. doi: 10.1158/0008-5472.CAN$15-2452$ therapies might therefore provide additional antitumor effects, albeit increased toxicity. Although several preclinical studies have demonstrated that mTOR inhibitors decrease tumor angiogenesis, this specific mechanism in the context of RCC has not been thoroughly investigated. More importantly, some investigations in RCC mouse models did not find any inhibitory effect of rapalogs on the tumor vasculature. Finally, in a subset of RCC that presents VHL mutation, the preferential inhibition of HIF- $1 \alpha$ over HIF- $2 \alpha$ by rapalogs might decrease the tumorsuppressing effects of HIF-1 $\alpha$, counteracting the anticancer efficacy of rapalogs. Given the success of immunotherapies, future investigations addressing the role of mTOR inhibitors in RCC will certainly focus on their immunostimulatory effects. Accordingly, dissecting the conditions where mTOR inhibitors exert immunostimulatory instead of immunosuppressing activities will be key. Interestingly, a study demonstrated that some RCC patients preferentially presented increased antitumor response under rapalog treatment, highlighting their therapeutic potential in combination with immunotherapy.

\section{AUTHOR CONTRIBUTIONS}

SF and OD designed the manuscript. SF drafted the manuscript. OD and ND revised the manuscript. All authors have approved the final version of the manuscript.

\section{FUNDING}

This work was supported by grants to SF (bourse pro-femmes from the University of Lausanne) and to OD (KFS-4128-02-2017 from the Swiss Cancer League).

Bruns, C. J., Koehl, G. E., Guba, M., Yezhelyev, M., Steinbauer, M., Seeliger, H., et al. (2004). Rapamycin-induced endothelial cell death and tumor vessel thrombosis potentiate cytotoxic therapy against pancreatic cancer. Clin. Cancer Res. 10, 2109-2119. doi: 10.1158/1078-0432.CCR03-0502

Cancer Genome Atlas Research. (2013). Comprehensive molecular characterization of clear cell renal cell carcinoma. Nature 499, 43-49. doi: $10.1038 /$ nature12222

Cho, D. C., Cohen, M. B., Panka, D. J., Collins, M., Ghebremichael, M., Atkins, M. B., et al. (2010). The efficacy of the novel dual PI3-kinase/mTOR inhibitor NVP-BEZ235 compared with rapamycin in renal cell carcinoma. Clin. Cancer Res. 16, 3628-3638. doi: 10.1158/1078-0432.CCR-09-3022

Choi, J., Enis, D. R., Koh, K. P., Shiao, S. L., and Pober, J. S. (2004). T lymphocyte-endothelial cell interactions. Annu. Rev. Immunol. 22, 683-709. doi: 10.1146/annurev.immunol.22.012703.104639

Davis, C. F., Ricketts, C. J., Wang, M., Yang, L., Cherniack, A. D., Shen, H., et al. (2014). The somatic genomic landscape of chromophobe renal cell carcinoma. Cancer Cell 26, 319-330. doi: 10.1016/j.ccr.2014.07.014

Diken, M., Kreiter, S., Vascotto, F., Selmi, A., Attig, S., Diekmann, J., et al. (2013). mTOR inhibition improves antitumor effects of vaccination with antigen-encoding RNA. Cancer Immunol Res. 1, 386-392. doi: 10.1158/2326-6066.CIR-13-0046

Dormond, O., Madsen, J. C., and Briscoe, D. M. (2007). The effects of mTORAkt interactions on anti-apoptotic signaling in vascular endothelial cells. J Biol Chem. 282, 23679-23686. doi: 10.1074/jbc.M700563200

Dufour, M., Dormond-Meuwly, A., Demartines, N., and Dormond, O. (2011). Targeting the Mammalian Target of Rapamycin (mTOR) in cancer therapy: 
lessons from past and future perspectives. Cancers (Basel) 3, 2478-2500. doi: $10.3390 /$ cancers 3022478

Dutcher, J. P., de Souza, P., McDermott, D., Figlin, R. A., Berkenblit, A., Thiele, A., et al. (2009). Effect of temsirolimus versus interferon-alpha on outcome of patients with advanced renal cell carcinoma of different tumor histologies. Med. Oncol. 26, 202-209. doi: 10.1007/s12032-009-9177-0

Ellis, L., Shah, P., Hammers, H., Lehet, K., Sotomayor, P., Azabdaftari, G., et al. (2012). Vascular disruption in combination with mTOR inhibition in renal cell carcinoma. Mol. Cancer Ther. 11, 383-392. doi: 10.1158/1535-7163.MCT-11-0748

Faes, S., Demartines, N., and Dormond, O. (2017a). Resistance to mTORC1 inhibitors in cancer therapy: from kinase mutations to intratumoral heterogeneity of kinase activity. Oxid. Med. Cell. Longev. 2017:1726078. doi: $10.1155 / 2017 / 1726078$

Faes, S., and Dormond, O. (2015). PI3K and AKT: unfaithful partners in cancer. Int. J. Mol. Sci. 16, 21138-21152. doi: 10.3390/ijms 160921138

Faes, S., Santoro, T., Demartines, N., and Dormond, O. (2017b). Evolving Significance and Future Relevance of Anti-Angiogenic Activity of mTOR Inhibitors in Cancer Therapy. Cancers (Basel). Nov 1;9. Epub 2017/11/07. doi: 10.3390 /cancers9110152

Garje, R., An, J., Greco, A., Vaddepally, R. K., and Zakharia, Y. (2020). The Future of immunotherapy-based combination therapy in metastatic renal cell carcinoma. Cancers (Basel) 12:143. doi: 10.3390/cancers12010143

Guba, M., von Breitenbuch, P., Steinbauer, M., Koehl, G., Flegel, S., Hornung, M., et al. (2002). Rapamycin inhibits primary and metastatic tumor growth by antiangiogenesis: involvement of vascular endothelial growth factor. Nat. Med. 8, 128-135. doi: $10.1038 / \mathrm{nm} 0202-128$

Gudas, L. J., Fu, L., Minton, D. R., Mongan, N. P., and Nanus, D. M. (2014). The role of HIF1alpha in renal cell carcinoma tumorigenesis. J. Mol. Med. (Berl.) 92, 825-836. doi: 10.1007/s00109-014-1180-z

Hoefflin, R., Harlander, S., Schafer, S., Metzger, P., Kuo, F., Schonenberger, D., et al. (2020). HIF-1alpha and HIF-2alpha differently regulate tumour development and inflammation of clear cell renal cell carcinoma in mice. Nat. Commun. 11:4111. doi: 10.1038/s41467-020-17873-3

Hsieh, J. J., and Cheng, E. H. (2016). A braided cancer river connects tumor heterogeneity and precision medicine. Clin. Transl. Med. 5:42. doi: 10.1186/s40169-016-0123-4

Hsieh, J. J., Manley, B. J., Khan, N., Gao, J., Carlo, M. I., and Cheng, E. H. (2017a). Overcome tumor heterogeneity-imposed therapeutic barriers through convergent genomic biomarker discovery: a braided cancer river model of kidney cancer. Semin. Cell Dev. Biol. 64, 98-106. doi: 10.1016/j.semcdb.2016.09.002

Hsieh, J. J., Purdue, M. P., Signoretti, S., Swanton, C., Albiges, L., Schmidinger, M., et al. (2017b). Renal cell carcinoma. Nat Rev Dis Primers. Mar 9;3:17009. Epub 2017/03/10. doi: 10.1038/nrdp.2017.9

Hudes, G., Carducci, M., Tomczak, P., Dutcher, J., Figlin, R., Kapoor, A., et al. (2007). Temsirolimus, interferon alfa, or both for advanced renal-cell carcinoma. N. Engl. J. Med. 356, 2271-2281. doi: 10.1056/NEJMoa066838

Huijts, C. M., Santegoets, S. J., de Jong, T. D., Verheul, H. M., de Gruijl, T. D., and van der Vliet, H. J. (2017). Immunological effects of everolimus in patients with metastatic renal cell cancer. Int. J. Immunopathol. Pharmacol. 30, 341-352. doi: 10.1177/0394632017734459

Ingels, A., Zhao, H., Thong, A. E., Saar, M., Valta, M. P., Nolley, R., et al. (2014). Preclinical trial of a new dual mTOR inhibitor, MLN0128, using renal cell carcinoma tumorgrafts. Int. J. Cancer 134, 2322-2329. doi: 10.1002/ijc.28579

Kondo, K., Kim, W. Y., Lechpammer, M., and Kaelin, W. G. Jr. (2003). Inhibition of HIF2alpha is sufficient to suppress pVHL-defective tumor growth. PLoS Biol. 1:E83. doi: 10.1371/journal.pbio.0000083

Kondo, K., Klco, J., Nakamura, E., Lechpammer, M., and Kaelin, W. G. Jr. (2002). Inhibition of HIF is necessary for tumor suppression by the von Hippel-Lindau protein. Cancer Cell. 1, 237-246. doi: 10.1016/S1535-6108(02)00043-0

Kotecha, R. R., Motzer, R. J., and Voss, M. H. (2019). Towards individualized therapy for metastatic renal cell carcinoma. Nat. Rev. Clin. Oncol. 16, 621-633. doi: 10.1038/s41571-019-0209-1

Kuroshima, K., Yoshino, H., Okamura, S., Tsuruda, M., Osako, Y., Sakaguchi, T., et al. (2020). Potential new therapy of Rapalink-1, a new generation mammalian target of rapamycin inhibitor, against sunitinib-resistant renal cell carcinoma. Cancer Sci. 111, 1607-1618. doi: 10.1111/cas.14395
Kwiatkowski, D. J., Choueiri, T. K., Fay, A. P., Rini, B. I., Thorner, A. R., de Velasco, G., et al. (2016). Mutations in TSC1, TSC2, and MTOR are associated with response to rapalogs in patients with metastatic renal cell carcinoma. Clin. Cancer Res. 22, 2445-2452. doi: 10.1158/1078-0432.CCR-15-2631

Lane, H. A., Wood, J. M., McSheehy, P. M., Allegrini, P. R., Boulay, A., Brueggen, J., et al. (2009). mTOR inhibitor RAD001 (everolimus) has antiangiogenic/vascular properties distinct from a VEGFR tyrosine kinase inhibitor. Clin. Cancer Res. 15, 1612-1622. doi: 10.1158/1078-0432.CCR-08-2057

Li, Q., Rao, R., Vazzana, J., Goedegebuure, P., Odunsi, K., Gillanders, W., et al. (2012). Regulating mammalian target of rapamycin to tune vaccinationinduced $\mathrm{CD} 8(+) \mathrm{T}$ cell responses for tumor immunity. J. Immunol. 188, 3080-3087. doi: 10.4049/jimmunol.1103365

Lin, F., Zhang, P. L., Yang, X. J., Prichard, J. W., Lun, M., and Brown, R. E. (2006). Morphoproteomic and molecular concomitants of an overexpressed and activated mTOR pathway in renal cell carcinomas. Ann. Clin. Lab. Sci. $36,283-293$

Ljungberg, B., Bensalah, K., Canfield, S., Dabestani, S., Hofmann, F., Hora, M., et al. (2015). EAU guidelines on renal cell carcinoma: 2014 update. Eur. Urol. 67, 913-924. doi: 10.1016/j.eururo.2015.01.005

Luan, F. L., Ding, R., Sharma, V. K., Chon, W. J., Lagman, M., and Suthanthiran, M. (2003). Rapamycin is an effective inhibitor of human renal cancer metastasis. Kidney Int. 63, 917-926. doi: 10.1046/j.1523-1755.2003.00805.x

Martin, J. D., Seano, G., and Jain, R. K. (2019). Normalizing function of tumor vessels: progress, opportunities, and challenges. Annu. Rev. Physiol. 81, 505-534. doi: 10.1146/annurev-physiol-020518-114700

Mineharu, Y., Kamran, N., Lowenstein, P. R., and Castro, M. G. (2014). Blockade of mTOR signaling via rapamycin combined with immunotherapy augments antiglioma cytotoxic and memory T-cell functions. Mol. Cancer Ther. 13, 3024-3036. doi: 10.1158/1535-7163.MCT-14-0400

Moch, H., Cubilla, A. L., Humphrey, P. A., Reuter, V. E., and Ulbright, T. M. (2016). The 2016 WHO classification of tumours of the urinary system and male genital organs-part a: renal, penile, and testicular tumours. Eur. Urol. 70, 93-105. doi: 10.1016/j.eururo.2016.02.029

Moore, E. C., Cash, H. A., Caruso, A. M., Uppaluri, R., Hodge, J. W., Van Waes, C., et al. (2016). Enhanced tumor control with combination mTOR and PD-L1 inhibition in syngeneic oral cavity cancers. Cancer Immunol. Res. 4, 611-620. doi: 10.1158/2326-6066.CIR-15-0252

Motzer, R. J., Escudier, B., Oudard, S., Hutson, T. E., Porta, C., Bracarda, S., et al. (2008). Efficacy of everolimus in advanced renal cell carcinoma: a doubleblind, randomised, placebo-controlled phase III trial. Lancet 372, 449-456. doi: 10.1016/S0140-6736(08)61039-9

Motzer, R. J., Hutson, T. E., Glen, H., Michaelson, M. D., Molina, A., Eisen, T., et al. (2015). Lenvatinib, everolimus, and the combination in patients with metastatic renal cell carcinoma: a randomised, phase 2, open-label, multicentre trial. Lancet Oncol. 16, 1473-1482. doi: 10.1016/S1470-2045(15) 00290-9

Mpekris, F., Voutouri, C., Baish, J. W., Duda, D. G., Munn, L. L., Stylianopoulos, T., et al. (2020). Combining microenvironment normalization strategies to improve cancer immunotherapy. Proc. Natl. Acad. Sci. U.S.A. 117, 3728-3737. doi: 10.1073/pnas.1919764117

Myers, A. L., Orr, W. S., Denbo, J. W., Ng, C. Y., Zhou, J., Spence, Y., et al. (2012). Rapamycin-induced tumor vasculature remodeling in rhabdomyosarcoma xenografts increases the effectiveness of adjuvant ionizing radiation. J. Pediatr. Surg. 47, 183-189. doi: 10.1016/j.jpedsurg.2011.10.034

Nabi, S., Kessler, E. R., Bernard, B., Flaig, T. W., and Lam, E. T. (2018). Renal cell carcinoma: a review of biology and pathophysiology. F1000Res. 7:307. doi: 10.12688/f1000research.13179.1

Pallet, N., and Legendre, C. (2013). Adverse events associated with mTOR inhibitors. Expert. Opin. Drug Saf. 12, 177-186. doi: $10.1517 / 14740338.2013 .752814$

Pantuck, A. J., Seligson, D. B., Klatte, T., Yu, H., Leppert, J. T., Moore, L., et al. (2007). Prognostic relevance of the mTOR pathway in renal cell carcinoma: implications for molecular patient selection for targeted therapy. Cancer 109, 2257-2267. doi: 10.1002/cncr.22677

Patel, P. H., Chadalavada, R. S., Chaganti, R. S., and Motzer, R. J. (2006). Targeting von Hippel-Lindau pathway in renal cell carcinoma. Clin. Cancer Res. 12, 7215-7220. doi: 10.1158/1078-0432.CCR-06-2254 
Powles, T., Lackner, M. R., Oudard, S., Escudier, B., Ralph, C., Brown, J. E., et al. (2016a). Randomized open-label phase II trial of apitolisib (GDC-0980), a novel inhibitor of the PI3K/Mammalian target of rapamycin pathway, versus everolimus in patients with metastatic renal cell carcinoma. J. Clin. Oncol. 34, 1660-1668. doi: 10.1200/JCO.2015.64.8808

Powles, T., Wheater, M., Din, O., Geldart, T., Boleti, E., Stockdale, A., et al. (2016b). A Randomised phase 2 study of AZD2014 versus everolimus in patients with vegf-refractory metastatic clear cell renal cancer. Eur Urol. 69, 450-456. doi: 10.1016/j.eururo.2015.08.035

Ravaud, A., Gross-Goupil, M., and Bellmunt, J. (2013). Combination therapy in metastatic renal cell cancer. Semin. Oncol. 40, 472-481. doi: 10.1053/j.seminoncol.2013.05.010

Rini, B. I., Bellmunt, J., Clancy, J., Wang, K., Niethammer, A. G., Hariharan, S., et al. (2014). Randomized phase III trial of temsirolimus and bevacizumab versus interferon alfa and bevacizumab in metastatic renal cell carcinoma: INTORACT trial. J. Clin. Oncol. 32, 752-759. doi: 10.1200/JCO.2013.50.5305

Rodriguez-Moreno, J. F., Apellaniz-Ruiz, M., Roldan-Romero, J. M., Duran, I., Beltran, L., Montero-Conde, C., et al. (2017). Exceptional response to temsirolimus in a metastatic clear cell renal cell carcinoma with an early novel MTOR-activating mutation. J. Natl. Compr. Canc. Netw. 15, 1310-1315. doi: $10.6004 /$ jnccn.2017.7018

Rodriguez-Pascual, J., Cheng, E., Maroto, P., and Duran, I. (2010). Emergent toxicities associated with the use of mTOR inhibitors in patients with advanced renal carcinoma. Anticancer Drugs 21, 478-486. doi: 10.1097/CAD.0b013e32833760bf

Roldan-Romero, J. M., Beuselinck, B., Santos, M., Rodriguez-Moreno, J. F., Lanillos, J., Calsina, B., et al. (2020). PTEN expression and mutations in TSC1, TSC2, and MTOR are associated with response to rapalogs in patients with renal cell carcinoma. Int. J. Cancer 146, 1435-1444. doi: 10.1002/ijc.32579

Roldan-Romero, J. M., Rodriguez-Moreno, J. F., Garcia-Donas, J., and RodriguezAntona, C. (2017). mTOR pathway mutations and response to rapalogs in RCC-Letter. Clin. Cancer Res. 23:5320. doi: 10.1158/1078-0432.CCR-17-1280

Saxton, R. A., and Sabatini, D. M. (2017). mTOR signaling in growth, metabolism, and disease. Cell 168, 960-976. doi: 10.1016/j.cell.2017.02.004

Schmittnaegel, M., and De Palma, M. (2017). Reprogramming tumor blood vessels for enhancing immunotherapy. Trends Cancer 3, 809-812. doi: 10.1016/j.trecan.2017.10.002

Schmittnaegel, M., Rigamonti, N., Kadioglu, E., Cassara, A., Wyser Rmili, C., Kiialainen, A., et al. (2017). Dual angiopoietin-2 and VEGFA inhibition elicits antitumor immunity that is enhanced by PD-1 checkpoint blockade. Sci. Transl. Med. 9:eaak9670. doi: 10.1126/scitranslmed.aak9670

Schnell, C. R., Stauffer, F., Allegrini, P. R., O’Reilly, T., McSheehy, P. M., Dartois, C., et al. (2008). Effects of the dual phosphatidylinositol 3kinase/mammalian target of rapamycin inhibitor NVP-BEZ235 on the tumor vasculature: implications for clinical imaging. Cancer Res. 68, 6598-6607. doi: 10.1158/0008-5472.CAN-08-1044

Schodel, J., Grampp, S., Maher, E. R., Moch, H., Ratcliffe, P. J., Russo, P., et al. (2016). Hypoxia, hypoxia-inducible transcription factors, and renal cancer. Eur Urol. 69, 646-657. doi: 10.1016/j.eururo.2015.08.007

Scholz, G., Jandus, C., Zhang, L., Grandclement, C., Lopez-Mejia, I. C., Soneson, C., et al. (2016). Modulation of mTOR signalling triggers the formation of stem cell-like memory $\mathrm{T}$ cells. EBioMedicine 4, 50-61. doi: 10.1016/j.ebiom.2016.01.019

Shen, C., Beroukhim, R., Schumacher, S. E., Zhou, J., Chang, M., Signoretti, S., et al. (2011). Genetic and functional studies implicate HIF1alpha as a $14 \mathrm{q}$ kidney cancer suppressor gene. Cancer Discov. 1, 222-235. doi: 10.1158/2159-8290.CD-11-0098

Shen, C., and Kaelin, W. G. Jr. (2013). The VHL/HIF axis in clear cell renal carcinoma. Semin Cancer Biol. 23, 18-25. doi: 10.1016/j.semcancer.2012.06.001

Thomas, D. L., Doty, R., Tosic, V., Liu, J., Kranz, D. M., McFadden, G., et al. (2011). Myxoma virus combined with rapamycin treatment enhances adoptive $\mathrm{T}$ cell therapy for murine melanoma brain tumors. Cancer Immunol. Immunother. 60, 1461-1472. doi: 10.1007/s00262-011-1045-Z

Thomas, G. V., Tran, C., Mellinghoff, I. K., Welsbie, D. S., Chan, E., Fueger, B., et al. (2006). Hypoxia-inducible factor determines sensitivity to inhibitors of mTOR in kidney cancer. Nat Med. 12, 122-127. doi: 10.1038/nm1337
Thoreen, C. C., Kang, S. A., Chang, J. W., Liu, Q., Zhang, J., Gao, Y., et al. (2009). An ATP-competitive mammalian target of rapamycin inhibitor reveals rapamycin-resistant functions of mTORC1. J. Biol. Chem. 284, 8023-8032. doi: 10.1074/jbc.M900301200

Tian, T., Li, X., and Zhang, J. (2019). mTOR signaling in cancer and mTOR inhibitors in solid tumor targeting therapy. Int. J. Mol. Sci. 20:755. doi: 10.3390/ijms20030755

Torii, S., Jinnouchi, H., Sakamoto, A., Kutyna, M., Cornelissen, A., Kuntz, S., et al. (2020). Drug-eluting coronary stents: insights from preclinical and pathology studies. Nat. Rev. Cardiol. 17, 37-51. doi: 10.1038/s41569-019-0234-x

Toschi, A., Lee, E., Gadir, N., Ohh, M., and Foster, D. A. (2008). Differential dependence of hypoxia-inducible factors 1 alpha and 2 alpha on MTORC1 and mTORC2. J Biol Chem. 283, 34495-34499. doi: 10.1074/jbc.C800170200

Uldry, E., Faes, S., Demartines, N., and Dormond, O. (2017). Fine-tuning tumor endothelial cells to selectively kill cancer. Int. J. Mol. Sci. 18:1401. doi: 10.3390/ijms18071401

Voss, M. H., Bastos, D. A., Karlo, C. A., Ajeti, A., Hakimi, A. A., Feldman, D. R., et al. (2014a). Treatment outcome with mTOR inhibitors for metastatic renal cell carcinoma with nonclear and sarcomatoid histologies. Ann. Oncol. 25, 663-668. doi: 10.1093/annonc/mdt578

Voss, M. H., Chen, D., Reising, A., Marker, M., Shi, J., Xu, J., et al. (2019). PTEN expression, not mutation status in TSC1, TSC2, or mTOR, correlates with the outcome on everolimus in patients with renal cell carcinoma treated on the randomized RECORD-3 trial. Clin. Cancer Res. 25, 506-514. doi: 10.1158/1078-0432.CCR-18-1833

Voss, M. H., Hakimi, A. A., Pham, C. G., Brannon, A. R., Chen, Y. B., Cunha, L. F., et al. (2014b). Tumor genetic analyses of patients with metastatic renal cell carcinoma and extended benefit from mTOR inhibitor therapy. Clin. Cancer Res. 20, 1955-1964. doi: 10.1158/1078-0432.CCR-13-2345

Waldner, M., Fantus, D., Solari, M., and Thomson, A. W. (2016). New perspectives on mTOR inhibitors (rapamycin, rapalogs and TORKinibs) in transplantation. Br. J. Clin. Pharmacol. 82, 1158-1170. doi: 10.1111/bcp.12893

Wang, C., Qin, L., Manes, T. D., Kirkiles-Smith, N. C., Tellides, G., and Pober, J. S. (2014). Rapamycin antagonizes TNF induction of VCAM-1 on endothelial cells by inhibiting mTORC2. J. Exp. Med. 211, 395-404. doi: 10.1084/jem.20131125

Wang, C., Yi, T., Qin, L., Maldonado, R. A., von Andrian, U. H., Kulkarni, S., et al. (2013). Rapamycin-treated human endothelial cells preferentially activate allogeneic regulatory $\mathrm{T}$ cells. J. Clin. Invest. 123, 1677-1693. doi: 10.1172/JCI66204

Wang, Y., Wang, X. Y., Subjeck, J. R., Shrikant, P. A., and Kim, H. L. (2011) Temsirolimus, an mTOR inhibitor, enhances anti-tumour effects of heat shock protein cancer vaccines. Br. J. Cancer 104, 643-652. doi: 10.1038/bjc.2011.15

Zhang, H., Berel, D., Wang, Y., Li, P., Bhowmick, N. A., Figlin, R. A., et al. (2013). A comparison of Ku0063794, a dual mTORC1 and mTORC2 inhibitor, and temsirolimus in preclinical renal cell carcinoma models. PLOS ONE 8:e54918. doi: 10.1371/journal.pone.0054918

Zhang, Q., Bindokas, V., Shen, J., Fan, H., Hoffman, R. M., and Xing, H. R. (2011). Time-course imaging of therapeutic functional tumor vascular normalization by antiangiogenic agents. Mol. Cancer Ther. 10, 1173-1184. doi: 10.1158/1535-7163.MCT-11-0008

Zheng, B., Mao, J. H., Qian, L., Zhu, H., Gu, D. H., Pan, X. D., et al. (2015). Pre-clinical evaluation of AZD-2014, a novel mTORC1/2 dual inhibitor, against renal cell carcinoma. Cancer Lett. 357, 468-475. doi: 10.1016/j.canlet.2014.11.012

Conflict of Interest: The authors declare that the research was conducted in the absence of any commercial or financial relationships that could be construed as a potential conflict of interest.

Copyright (C) 2021 Faes, Demartines and Dormond. This is an open-access article distributed under the terms of the Creative Commons Attribution License (CC BY). The use, distribution or reproduction in other forums is permitted, provided the original author(s) and the copyright owner(s) are credited and that the original publication in this journal is cited, in accordance with accepted academic practice. No use, distribution or reproduction is permitted which does not comply with these terms. 